\title{
IMPACT OF THE PULSE WIDTH MODULATION ON THE TEMPERATURE DISTRIBUTION IN THE ARMATURE OF A SOLENOID VALVE
}

\author{
R. GORAJ \\ Paul Gossen Str. 99 \\ 91052, Erlangen, GERMANY \\ E-mail: robertgoraj@gmx.de
}

\begin{abstract}
In order to estimate the inductive power set in the armature of the high-speed solenoid valve (HSV) during the open loop control (OLC) using pulse width modulation (PWM) an analytical explicit formula has been derived. The simplifications taken both in the geometry and in the physical behavior of the HSV were described. The inductive power was calculated for different boundary conditions and shown as a function of the frequency of the coil current. The power set in the armature was used as an input to the thermal calculation. The thermal calculation had an objective to estimate the time dependent temperature distribution in the armature of the HSV. All the derivation steps were presented and the influence of different boundary conditions was shown and discussed. The increase of the temperature during the heating with inductive power has been evaluated both in the core and on the side surface of the HSV.
\end{abstract}

Key words: solenoid valve, armature, inductive power, PWM, temperature.

\section{Introduction}

Even though there are lots of research reports on the subject of the HSV, most of them focus on the modeling, dynamic response experiment and control method of the HSV (Peng et al., 2004). In Bottauscio et al. (2004) finite-element approaches of electromechanical dynamics were presented. In Huber and Ulbrich (2014) a simulation model of a solenoid valve was developed and validated. The method of closed loop control for the closure time and hold current was developed in Shahroudi et al. (2006) and in Lu et al. (2014) the authors investigated the impact of different control strategies of the switch-on time. One popular digital technique in hydraulics is the switching technique known as the PWM method. This type of control of the HSV offers the ability to provide position control of hydraulic actuators at a low costs (Wei Ying Lai et al., 2015). The PWM-based control of solenoid valves was a subject of investigation in Sean Hodgson et al. (2015). Solenoid valves are nowadays studied in the early stage of system development. One of these studies regards the investigation of temperature distribution and thermal deformations inside the HSV (Angadi et al., 2009). The objective of this paper is to contribute to the investigation of the influence of the PWM method on the temperature distribution in the armature of HSVs.

\section{Notation of mathematical formulas}

In order to minimise the length of mathematic formulas presented in the paper the following shortened notation has been used:

$>$ Scalar variables and parameter are written in italics.

$>$ Vector variables are written in normal fonts.

$>$ Derivatives are indicated using the down index of the state variable. The state variables are the following $r, \varphi, z, t$. 
Partial derivatives a state variable are written in italics.

In the case of the total derivative in time the straight writing " $\mathrm{t}$ " is used.

Components of a vector are indicated using the upper index.

A few examples of the shorten notation are shown in Tab.1.

Table 1. Examples of notations of mathematical formulas.

\begin{tabular}{|c|c|c|}
\hline description & one of conventional notations & short notation \\
\hline partial derivative of a scalar function $u$ & $\frac{\partial u}{\partial r}$ & $u_{r}$ \\
\hline total derivative of the vector function $\boldsymbol{u}$ & $\frac{d \mathbf{u}}{d t}$ & $\mathbf{u}_{\mathrm{t}}$ \\
\hline differential operator & $\frac{\partial}{\partial r}$ & $\partial_{r}$ \\
\hline mixed derivative of the $z$ - component of the vector $\boldsymbol{u}$ & $\frac{\partial^{2} u_{z}}{\partial r \partial \varphi}$ & $u_{r \varphi}^{z}$ \\
\hline
\end{tabular}

\section{Inductive power}

During the PWM control the amplitude of the electric voltage varies between a minimum and a maximum value. The duration of the switch-on and the switch-off phase is different and chosen in a precise way. The ratio of the switch-on and the switch-off time determines (among others) the upper and lower value of the electric current flowing in the coil of the HSV. The purpose of the switching is to keep the mean value of the coil current constant. The course of the current during the control with PWM is similar to the sawfunction. The time-variable electric current implies the change of the magnetic field in the HVS and causes eddy currents in the armature. An inductive power losses are set to the armature and cause an unwanted increase of temperature. In order to find the inductive power one can use Maxwell's equations (Jackson, 2006).

$$
\begin{aligned}
& \nabla \times \mathrm{E}=-\mathrm{B}_{t}, \\
& \nabla \times \mathrm{H}=\sigma \mathrm{E}+\mathrm{D}_{t}, \\
& \nabla \cdot \mathrm{D}=\rho, \quad \nabla \cdot \mathrm{B}=0, \\
& \mathrm{D}=\varepsilon \mathrm{E}, \quad \mathrm{J}=\sigma \mathrm{E}, \quad \mathrm{B}=\mu \mathrm{H} .
\end{aligned}
$$

From Maxwell's equations one can derive Helmholz's equations (Rawa, 2001) which are the basis for the calculation of electromagnetic waves.

$$
\begin{gathered}
\Delta \mathrm{E}-(\nabla \times \mathrm{E}) \times \nabla(\ln \mu)=\sigma \mu \partial_{t} \mathrm{E}+\varepsilon \mu \partial_{t t} \mathrm{E}, \\
\Delta \mathrm{H}+\nabla(\mathrm{H} \cdot \nabla(\ln \mu))=\sigma \mu \partial_{t} \mathrm{H}+\varepsilon \mu \partial_{t t} \mathrm{H} .
\end{gathered}
$$

For the estimation of inductive power losses the magnetic circuit of the HSV was simplified to the layout shown in Fig.1. 

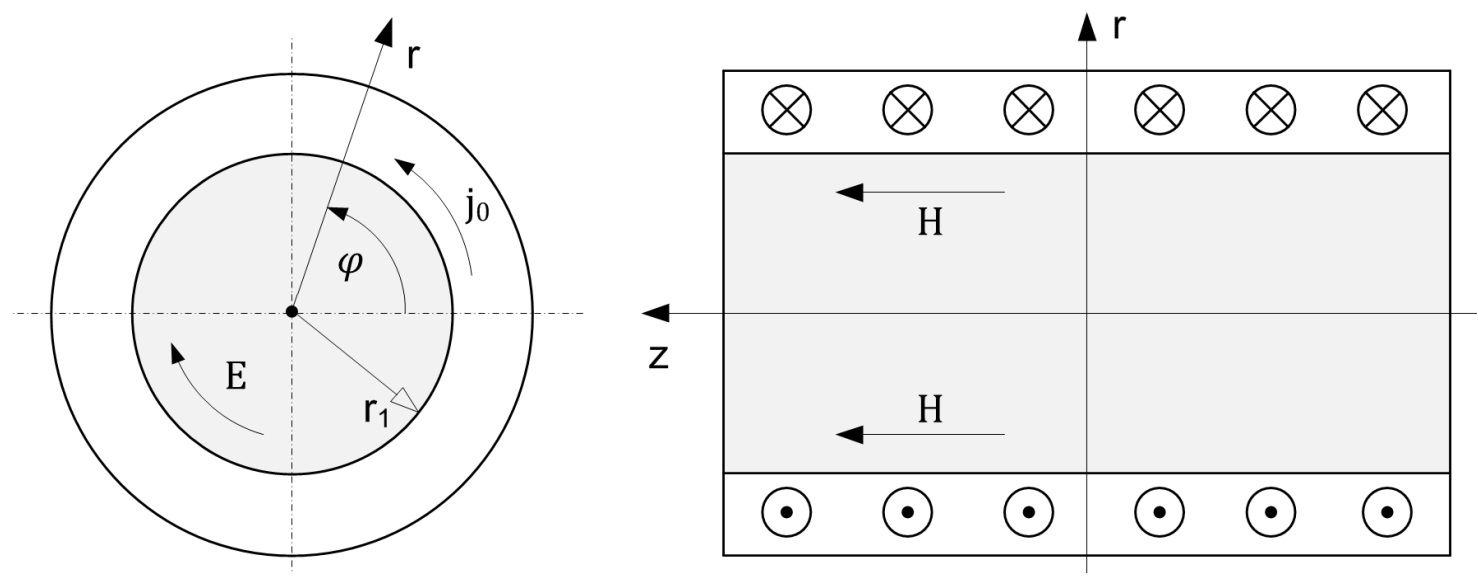

Fig.1. Simplified layout armature/coil.

Furthermore it was assumed that:

a) permeability of the armature is constant,

b) electrical conductivity of the armature $\sigma \gg \varepsilon \omega$,

c) the armature is placed concentrically in the magnet yoke,

d) the armature is an infinite long cylinder.

The investigations were restricted only to the fundamental wave of the saw-function of electric current which has the frequency equal to $f=2 \pi \omega$. Under these assumptions Eqs (3.5), (3.6) simplify

$$
\begin{aligned}
& \underline{E}_{r r}^{\varphi}+r^{-1} \underline{E}_{r}^{\varphi}-r^{-2} \underline{E}^{\varphi}=\Lambda^{2} \underline{E}^{\varphi}, \\
& \underline{H}_{r r}^{z}+r^{-1} \underline{H}_{r}^{z}=\Lambda^{2} \underline{H}^{z} .
\end{aligned}
$$

The boundary conditions of Eqs (3.7), (3.8) are

$$
\begin{aligned}
& \underline{E}^{\varphi}(0)=0, \\
& \left.\underline{H}_{r}^{z}\right|_{r=0}=0 .
\end{aligned}
$$

The parameter $\Lambda$ in Eqs (3.7), (3.8) is the propagation constant

$$
\Lambda^{2}=j \omega \sigma \mu
$$

Under the use of the calculation rule Eq.(3.12) for the complex number $z$ (Bronstein et al., 2000)

$$
\sqrt[n]{z}=\sqrt[n]{|z|}\left(\cos \frac{\arg z+2 \pi k}{n}+i \cos \frac{\arg z+2 \pi k}{n}\right) \quad \text { for } \quad k=0,1, \ldots, n-1
$$

can the propagation constant $\Lambda$ be expressed as follows

$$
\Lambda=1 / \delta+j / \delta
$$


The constant $\delta$ in Eq.(3.13) is the penetration depth of the electromagnetic wave defined as in Conraths (1992).

$$
\delta=\sqrt{2(\omega \sigma \mu)^{-1}}
$$

The solution to the equation system (3.7) - (3.10) is

$$
\begin{aligned}
& \underline{E}^{\varphi}=-\Lambda \sigma^{-1} \frac{\theta_{a}}{\left(L_{h}-L_{m}\right)} \frac{I_{1}(\Lambda r)}{I_{0}\left(\Lambda r_{l}\right)}, \\
& \underline{H}^{z}=\frac{\theta_{a}}{\left(L_{h}-L_{m}\right)} \frac{I_{0}(\Lambda r)}{I_{0}\left(\Lambda r_{l}\right)} .
\end{aligned}
$$

For the derivation of Eqs (3.15), (3.16) see appendix A. By means of electric and magnetic field intensities one can build the Poynting vector (Mrozynski, 2003)

$$
\underline{\mathrm{S}}=2^{-1} \underline{\mathrm{E}} \times \underline{\mathrm{H}}^{*}
$$

The time mean value of the inductive power set in the armature of the HSV can be obtained after the integration of the Poynting vector over the armature side surface $\mathrm{A}_{v}$ (Mrozynski, 2003).

$$
P_{v}=-2^{-1} \operatorname{Re}\left\{\oint_{A}\left(\underline{\mathrm{E}}\left(r_{1}\right) \times \underline{\mathrm{H}}^{*}\left(r_{1}\right)\right) d \mathrm{~A}_{v}\right\} .
$$

The vectorial armature side surface $A_{v}$ is in cylindrical co-ordinate system equal to

$$
d \mathrm{~A}_{v}=r_{l} d \varphi d z \mathrm{e}^{r}
$$

Setting Eq.(3.19) in Eq.(3.18) and the building of the cross product $\underline{\mathrm{E}}\left(r_{1}\right) \times \underline{\mathrm{H}}^{*}\left(r_{1}\right)$ result in

$$
P_{v}=-2^{-1} r_{l} \operatorname{Re}\left\{\underline{E}^{\varphi}\left(r_{l}\right)\left(\underline{H}^{z}\left(r_{l}\right)^{*}\right)\right\} \int_{0}^{2 \pi} d \varphi \int_{0}^{L_{h}-L_{m}} d z .
$$

The setting of Eqs (3.15) and (3.16) in Eq.(3.20) yields finally the inductive power set in the armature.

$$
P_{v}=\pi \frac{r_{1}}{L_{h}-L_{m}} \frac{\theta_{a}^{2}}{\sigma} \operatorname{Re}\left\{\Lambda \frac{I_{1}\left(\Lambda r_{1}\right)}{I_{0}\left(\Lambda r_{1}\right)}\right\}
$$

In the next section the formula Eq.(3.21) has been evaluated. The calculation results will further be used for the calculation of the temperature distribution in the armature. 


\section{Calculation results of inductive power}

The inductive power set in the armature was analysed in the frequency range of the coil current from zero to $25[\mathrm{kHz}]$. The parameters of the armature for which analyses were performed are listed in Tab.2. Some of these parameters will further be used in the calculation of the temperature of the armature.

Table 2. Parameters of the armature of the HSV.

\begin{tabular}{|c|c|c|}
\hline Symbol & value & unit \\
\hline$\sigma$ & $1.4 \cdot 10^{6}$ & $\mathrm{~S} / \mathrm{m}$ \\
\hline$\mu$ & $1000 \cdot 4 \pi \cdot 10^{-7}$ & $\mathrm{Vs} /(\mathrm{Am})$ \\
\hline$\rho$ & 7700 & $\mathrm{~kg} / \mathrm{m}^{3}$ \\
\hline$c_{p}$ & 460 & $\mathrm{~J} /(\mathrm{kgK})$ \\
\hline$\lambda$ & 25 & $\mathrm{~W} /(\mathrm{mK})$ \\
\hline$L_{m}$ & 3 & $\mathrm{~mm}$ \\
\hline$L_{h}$ & 10 & $\mathrm{~mm}$ \\
\hline
\end{tabular}

The analysis of the inductive power was performed for different armature radii and different electromotoric forces. In Tab. 3 the overview of the analyzed evaluation points is shown.

Table 3. Analyzed evaluation points.

\begin{tabular}{|c|c|c|}
\hline evaluation point & $r_{1}[\mathrm{~mm}]$ & $\theta_{a}[A]$ \\
\hline$P_{1}$ & 6 & 7 \\
\hline$P_{2}$ & 7 & 7 \\
\hline$P_{3}$ & 7 & 9 \\
\hline
\end{tabular}

The frequency dependent inductive power set in the armature together with the penetration depth of the electromagnetic wave is shown in Fig.2. The inductive power in the examined frequency range lies for all evaluation points under $3[\mathrm{~W}]$. The penetration depth drops under $250[\mu \mathrm{m}]$ for frequencies higher by roughly $3[\mathrm{kHz}]$.
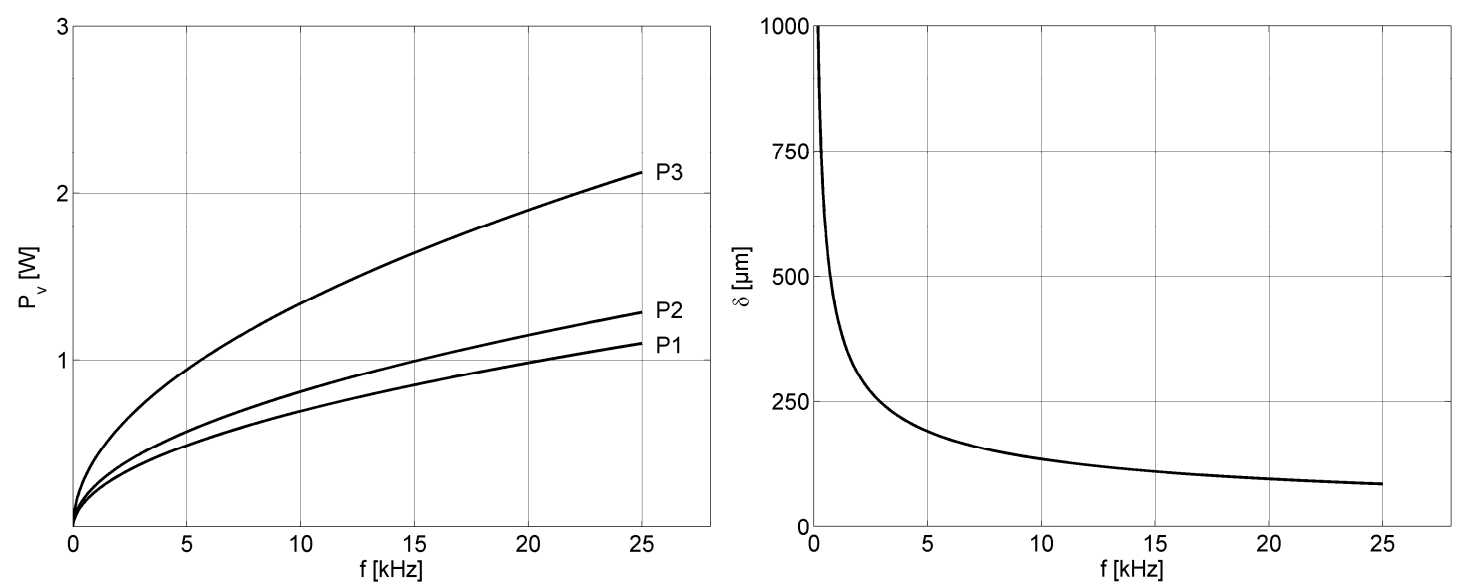

Fig.2. Inductive power set in the armature penetration depth of the electromagnetic wave. 
In the analysis the frequency of $15[\mathrm{kHz}]$ is of particular interest. At this frequency the inductive power in the evaluation point $P_{1}$ is about $0.9[\mathrm{~W}]$, in the evaluation point $P_{2}$ equal to $1[\mathrm{~W}]$ and in the evaluation point $P_{3}$ equal to $1.6[\mathrm{~W}]$. The penetration depth at the frequency of $15[\mathrm{kHz}]$ is equal to $110[\mu \mathrm{m}]$.

\section{Time dependent temperature distribution}

The estimation of the temperature distribution was carried out under the assumption of isothermal separated armature from the surroundings of the HSV. The inductive power was the single heat source for the calculation. The calculation was made by means of the analytical solution to the heat equation (Grigull and Sander, 1990).

$$
-\nabla \cdot(\lambda \nabla T)+\rho c_{p} T_{\mathrm{t}}=\dot{q}_{v}
$$

In the considered calculation case is the frequency of the fundamental wave of the coil current in the range of some kilohertz. For the frequency of e.g., $f=15[\mathrm{kHz}]$ see the threefold penetration depth of an electromagnetic wave in the armature is equal to $3 \delta=330[\mu \mathrm{m}]$ (Appendix C or Fig.2 on the right). That means that almost all the inductive power losses in the armature (for the threefold penetration depth $1-\exp (3 \delta) \cong 95[\%])$ are placed in closed surroundings of the armature side surface. Because of it, the inductive power was treated as the surface power density and calculated (using Eq.(3.21)) as follows

$$
\dot{q}_{c} \equiv P_{v}\left(2 \pi r_{l} L_{h}\right)^{-1}=\frac{1}{L_{h}-L_{m}} \frac{\theta_{a}^{2}}{\sigma L_{h}} \operatorname{Re}\left\{\Lambda \frac{I_{l}\left(\Lambda r_{l}\right)}{I_{0}\left(\Lambda r_{l}\right)}\right\} .
$$

Under this assumption Eq.(5.1) simplifies in the cylindrical co-ordinate system for $\lambda$-const. To

$$
b r^{-1} \partial_{r}\left(r T_{r}\right)=T_{\mathrm{t}}
$$

The parameter $b$ in Eq.(5.3) is the thermal diffusivity

$$
b=\lambda\left(\rho c_{p}\right)^{-1} .
$$

The parameter $\dot{q}_{c}$ was used for the definition of boundary conditions of Eq.(5.3)

$$
\begin{aligned}
& \left.\lambda T_{r}\right|_{r=r_{I}}=\dot{q}_{c}, \\
& \left.T_{r}\right|_{r=0}=0 .
\end{aligned}
$$

The derivation of the solution to Eqs (5.3) - (5.6) is shown in the appendix B. The time dependent temperature distribution in the armature can be estimated using 


$$
T(r, t)=2 \dot{q}_{c} b\left(\lambda r_{l}\right)^{-1}\left(t+\frac{r^{2}}{4 b}-\frac{r_{l}^{2}}{8 b}\right)-2 \dot{q}_{c} r_{l} \lambda^{-1} \sum_{n=0}^{\infty} \frac{J_{0}\left(\gamma_{n} r r_{l}^{-1}\right)}{\gamma_{n}^{2} J_{0}\left(\gamma_{n}\right)} e^{-\gamma_{n}^{2} r_{l}^{-2} b t}
$$

\section{Calculation results of the temperature of the armature}

The temperature distribution in the armature was analysed in the time range from zero to $10[\mathrm{~s}]$. The parameters of the armature for which the analysis was performed are listed in Tab.2 The evaluation points are the same as in the calculation cases of the inductive power. These parameters are listed in Tab. 3 The analysis was performed for the frequency of the current equal to $15[\mathrm{kHz}]$. The calculation results are shown in Fig.3.
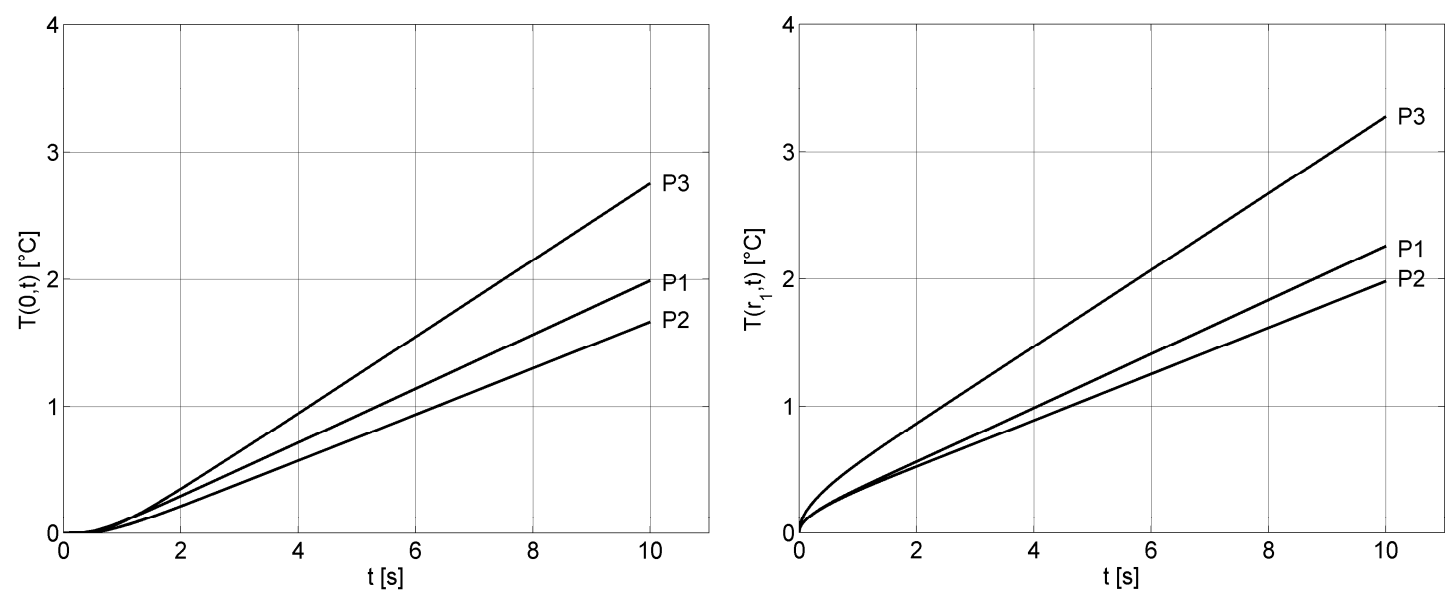

Fig.3. Temperature couse in the core (left) and on the side surface of the armature for the frequency of the coil current equal to $15[\mathrm{kHz}]$.

The maximum temperature increase of the core of the armature at the considered evaluation points lies under $3\left[{ }^{\circ} \mathrm{C}\right]$. After the heating time of $10[\mathrm{~s}]$ the biggest temperature increase of $2.8\left[{ }^{\circ} \mathrm{C}\right]$ occurs at the evaluation point $P_{3}$. The difference of the temperature increase between evaluation points $P_{3}$ and $P_{1}$; in this case it is about $1\left[{ }^{\circ} \mathrm{C}\right]$. The temperature increase at the evaluation point $P_{2}$ is smaller than the temperature increase at the evaluation point $P_{1}$ despite a bigger inductive heat set in the armature.

The maximum temperature increase on the side surface of the armature at the considered evaluation points lies under $4\left[{ }^{\circ} \mathrm{C}\right]$. After the heating time of $10[\mathrm{~s}]$ the biggest temperature increase of $3.3\left[{ }^{\circ} \mathrm{C}\right]$ occurs in at evaluation point $P_{3}$. The temperature increase at the evaluation point $P_{2}$ is in this case equal to $2\left[{ }^{\circ} \mathrm{C}\right]$ and at the evaluation point $P_{1}-2.3\left[{ }^{\circ} \mathrm{C}\right]$.

\section{Conclusions}

The increase of the armature radius from $6[\mathrm{~mm}]$ to $7[\mathrm{~mm}]$ due to the unchanged electro-motoric force equal to $7[A]$ caused for the maximal examined current frequency equal to $25[\mathrm{kHz}]$ the increase of the inductive power of about $0.2[\mathrm{~W}]$. The increase of the armature radius from $6[\mathrm{~mm}]$ to $7[\mathrm{~mm}]$ due to the simultaneous increase of the electro-motoric force from $7[A]$ to $9[A]$ caused for the current frequency 
$25[\mathrm{kHz}]$ the increase of the inductive power of about $1[\mathrm{~W}]$. In the case of the armature radius $7[\mathrm{~mm}]$, the electro-motoric force $9[A]$ and the current frequency $15[\mathrm{kHz}]$ the inductive power equal $1.6[\mathrm{~W}]$ caused after the heating time of $10[\mathrm{~s}]$ the increase of the temperature in the armature core of about $2.8\left[{ }^{\circ} \mathrm{C}\right]$. In this calculation case the difference between the temperature increase on the side surface of the armature and in the core of armature was about $0.5\left[{ }^{\circ} \mathrm{C}\right]$.

\section{Appendix A. Derivation of the formula for the calculation of inductive power}

The solutions to Eqs (3.7) and (3.8) are modified Bessel functions of first and second kind.

$$
\begin{aligned}
& \underline{E}^{\varphi}=C_{1} I_{1}(\Lambda r)+C_{2} K_{l}(\Lambda r), \\
& \underline{H}^{z}=C_{3} I_{0}(\Lambda r)+C_{4} K_{0}(\Lambda r) .
\end{aligned}
$$

From the boundary condition (3.9) it follows

$$
\operatorname{Re}\left\{\lim _{x \rightarrow 0} K_{l}(x \sqrt{j})\right\}=\infty
$$

The use of Eq.(A.3) implies for the constant $C_{2}$

$$
C_{2}=0 .
$$

The boundary conditions are given by Eq.(3.10) results in Tautz (1971)

$$
C_{3} \Lambda I_{1}(0)-C_{4} \Lambda K_{l}(0)=0 .
$$

Under the usage of Eq.(A.3) one gets for the constant $C_{4}$

$$
C_{4}=0 \text {. }
$$

The estimation of the further constant follows under the implementation of Faraday's law. The use of Eq.(3.1) yields

$$
r^{-1} \partial_{r}\left(r \underline{E}^{\varphi}\right)=-j \omega \mu \underline{H}^{z} .
$$

The left side of Eq.(A.7) becomes under the use of Eqs (A.1), (A.4) and the chain rule of differentiation

$$
r^{-1} \underline{E}^{\varphi}+\underline{E}_{r}^{\varphi}=C_{l} r^{-1} I_{l}(\Lambda r)+C_{l} \partial_{r}\left(I_{l}(\Lambda r)\right) .
$$

The last term of Eq.(A.8) can be written as

$$
C_{l} \partial_{r}\left(I_{l}(\Lambda r)\right)=C_{l} \partial_{\Lambda r}\left(I_{l}(\Lambda r)\right) \partial_{r}(\Lambda r) .
$$


The two derivatives of the right side of Eq.(A.9) are

$$
\begin{aligned}
& \partial_{\Lambda r}\left(I_{l}(\Lambda r)\right)=I_{0}(\Lambda r)-(\Lambda r)^{-1} I_{1}(\Lambda r), \\
& \partial_{r}(\Lambda r)=\Lambda .
\end{aligned}
$$

The setting of Eqs (A.8)-(A.11) and Eqs (A.2), (A.6) in Eq.(A.7) yields

$$
C_{1} \Lambda=-j \omega \mu C_{3}
$$

The use of Eq.(3.11) in Eq.(A.12) results in

$$
C_{1} / C_{3}=-\Lambda \sigma^{-1}
$$

The estimation of $C_{3}$ follows under the use of Ampère's circuital law. For the magnetic field intensity was assumed with Eq.(3.2) that

$$
\underline{H}^{z}\left(r=r_{l}\right)\left(L_{h}-L_{m}\right) \equiv \theta_{a}
$$

The use of Eqs (A.2) and (A.6) in Eq.(A.14) yields

$$
C_{3}=\frac{\theta_{a}}{I_{0}\left(\Lambda r_{1}\right)\left(L_{h}-L_{m}\right)}
$$

After the use of Eq.(A.15) in Eqs (A.1) and (A.2) one obtains the solution to the equation system Eqs $(3.7)-(3.10)$

$$
\begin{aligned}
& \underline{E}^{\varphi}=-\Lambda \sigma^{-1} \frac{\theta_{a}}{\left(L_{h}-L_{m}\right)} \frac{I_{1}(\Lambda r)}{I_{0}\left(\Lambda r_{1}\right)}, \\
& \underline{H}^{z}=\frac{\theta_{a}}{\left(L_{h}-L_{m}\right)} \frac{I_{0}(\Lambda r)}{I_{0}\left(\Lambda r_{l}\right)}
\end{aligned}
$$

\section{Appendix B. Derivation of the formula for the calculation of the time dependent temperature distribution}

The initial condition to Eq.(5.3) is

$$
\left.T\right|_{t=0}=0
$$

The equation Eq.(5.3) becomes after the use of Eq.(B.1) and the Laplace transformation (Krysinski and Wlodarski, 1998)

$$
r^{-1} \partial_{r}\left(r \underline{T}_{r}\right)=q \underline{T}
$$


The variable $\underline{T}$ in Eq.(B.2) is a complex temperature given with Długosz (2005)

$$
\underline{T}(r, s)=\int_{0}^{t} T(r, t) e^{-s t} d t .
$$

The parameter $q$ in Eq.(B.2) is

$$
q=\sqrt{s / b} .
$$

The boundary conditions of Eq.(B.2) become

$$
\begin{aligned}
& \left.\lambda \underline{T}_{r}\right|_{r=r_{l}}=s^{-1} \dot{q}_{c}, \\
& \left.\underline{T}_{r}\right|_{r=0}=0 .
\end{aligned}
$$

The solution to Eq.(B.2) is given by modified Bessel functions of first and second kind (Leitner and Zacharski, 1998)

$$
\underline{T}=C_{1} I_{0}(q r)+C_{2} K_{0}(q r) .
$$

The derivative of Eq.(B.7) is

$$
\underline{T}_{r}=C_{1} q I_{1}(q r)-C_{2} q K_{l}(q r) .
$$

The use of Eq.(B.6) together with Eq.(A.3) yields

$$
C_{2}=0 .
$$

After the use of Eq.(B.5) one gets

$$
C_{1}=\frac{\dot{q}_{c}}{\lambda s q I_{1}\left(q r_{l}\right)} .
$$

The setting of Eqs (B.9) and (B.10) in Eq.(B.7) yields the complex temperature distribution in the armature

$$
\underline{T}=\frac{\dot{q}_{c} I_{0}(q r)}{\lambda s q I_{1}\left(q r_{1}\right)}=\frac{f_{1}}{f_{2}} .
$$

Now the correspondence of Eq.(B.11) is quested. First, one must determine how many poles has the complex function Eq.(B.11). The modified Bessel function can be split in Taylor series as follows (Jackson, 2006). 


$$
I_{v}(x)=\sum_{n=1}^{\infty} \frac{(x / 2)^{2 n+v}}{\Gamma(n+v+1) n !}
$$

The parameter $\Gamma$ in Eq.(B.12) is the gamma function. For natural numbers it is defined as Nielsen (1906).

$$
\Gamma(n+1)=n !
$$

The use of Eqs (B.12) and (B.13) in Eq.(B.11) results in

$$
\underline{T}=\frac{\dot{q}_{c}}{\lambda} \frac{1}{s q} \frac{1+4^{-1}(q r)^{2}+64^{-1}(q r)^{4}+\ldots}{2^{-1} q r_{1}+16^{-1}\left(q r_{1}\right)^{3}+384^{-1}\left(q r_{1}\right)^{5}+\ldots} .
$$

The setting of Eq.(B.4) in Eq.(B.14) yields

$$
\underline{T}=\frac{2 b \dot{q}_{c}}{\lambda r_{1}} \frac{1}{s^{2}} \frac{1+4^{-1} b^{-1} r^{2} s+64^{-1} b^{-2} r^{4} s^{2}+\ldots}{1+8^{-1} b^{-1} r_{1}^{2} s+192^{-1} b^{-2} r_{1}^{4} s^{2}+\ldots} .
$$

From Eq.(B.15) one can see that the complex temperature distribution has a double pole in $s=0$. Other poles can be found using the Eq.(B.16) (Burg et al., 1994).

$$
I_{v}(x)=j^{-v} J_{v}(i x) .
$$

The setting of Eq.(B.16) in Eq.(B.11) yields

$$
\underline{T}=j \frac{\dot{q}_{c} J_{0}(j q r)}{\lambda s q J_{l}\left(j q r_{l}\right)} .
$$

One obtains other poles after the solution of the characteristic equation

$$
J_{l}(\gamma)=0
$$

The parameter $\gamma$ in Eq.(B.18) is

$$
\gamma=j q r_{1}
$$

The Eq.(B.18) concerns single poles. Solving Eq.(B.19) under the use of Eq.(B.4) yields these poles

$$
s_{n}=-b\left(\gamma_{n} / r_{1}\right)^{2}, \quad n=1,2, \ldots
$$

Now one can perform the reverse Laplace transformation. In the case of a double pole and $n$ single poles the correspondence to Eq.(B.17) can be found using the expansion in Laurent series (Dlugosz, 2005)

$$
T=c_{-1}+\sum_{n=0}^{\infty} \frac{f_{1}\left(s_{n}\right)}{\left.\partial_{s} f_{2}\right|_{s=s_{n}}} e^{s_{n} t}
$$


The parameter $c_{-1}$ in Eq.(B.21) is equal to Taler and Duda (2003)

$$
\begin{aligned}
& c_{-1}=D^{-1}\left(A t+B-A E D^{-1}\right), \\
& A=2 \dot{q}_{c} b\left(\lambda r_{1}\right)^{-1}, \\
& B=\dot{q}_{c} r^{2}\left(2 \lambda r_{l}\right)^{-1}, \\
& D=1, \\
& E=r_{1}^{2}(8 b)^{-1} .
\end{aligned}
$$

The derivative of $f_{2}$ can be obtained using the chain rule of differentiation (see also Eq.(B.11))

$$
\left.\partial_{s} f_{2}\right|_{s=s_{n}}=I_{l}\left(q r_{l}\right) \partial_{s}(\lambda s q)+\left.\lambda s q \partial_{s} I_{l}\left(q r_{l}\right)\right|_{s=s_{n}} .
$$

The first term of the right side of Eq.(B.27) is equal to zero because of Eq.(B.16) and because of the characteristic Eq.(B.18). The second term of the right side of Eq.(B.27) can be simplified using the relation Eq.(A.10) as follows

$$
\left.\lambda s q \partial_{s} I_{1}\left(q r_{1}\right)\right|_{s=s_{n}}=\left.\lambda s q\left(I_{0}\left(q r_{1}\right)-\left(q r_{1}\right)^{-1} I_{l}\left(q r_{l}\right)\right) r_{l}(2 b q)^{-1}\right|_{s=s_{n}}
$$

The use of Eqs (B.18) and (B.4) in Eq.(B.28) results in a further simplification

$$
\left.\partial_{s} f_{2}\right|_{s=s_{n}}=\frac{\lambda r_{1}}{2 b} s_{n} I_{0}\left(\sqrt{\frac{s_{n}}{b}} r_{1}\right) \text {. }
$$

The relation Eq.(B.29) can be written after the use of Eqs (B.16) and (B.19) as follows

$$
\left.\partial_{s} f_{2}\right|_{s=s_{n}}=-\left(2 r_{l}\right)^{-1} \lambda \gamma_{n}^{2} J_{0}\left(\gamma_{n}\right)
$$

The setting of Eqs (B.16) and (B.19) in the numerator of Eq.(B.11) yields

$$
f_{l}=\dot{q}_{c} J_{0}\left(\gamma_{n} r r_{l}^{-1}\right)
$$

After the setting of the relations Eqs (B.22) - (B.26) and (B.30), (B.31) in Eq.(B.21) one finally obtains the time dependent temperature distribution in the armature of the SV

$$
T(r, t)=2 \dot{q}_{c} b\left(\lambda r_{1}\right)^{-1}\left(t+\frac{r^{2}}{4 b}-\frac{r_{1}^{2}}{8 b}\right)-2 \dot{q}_{c} r_{1} \lambda^{-1} \sum_{n=0}^{\infty} \frac{J_{0}\left(\gamma_{n} r r_{1}^{-1}\right)}{\gamma_{n}^{2} J_{0}\left(\gamma_{n}\right)} e^{-\gamma_{n}^{2} r_{I}^{-2} b t}
$$




\section{Appendix C. Overview of calculation results}

Table 4. Selected calculation results.

\begin{tabular}{|c|c|c|c|c|c|}
\hline$f[\mathrm{kHz}]$ & $\delta[\mu m]$ & $\begin{array}{c}\text { calculation } \\
\text { point }\end{array}$ & $P_{v}[W]$ & $T(0,10 s)\left[{ }^{\circ} \mathrm{C}\right]$ & $T\left(r_{1}, 10 s\right)\left[{ }^{\circ} \mathrm{C}\right]$ \\
\hline \multirow{3}{*}{10} & \multirow{3}{*}{135} & $P_{1}$ & 0.6928 & 1.6192 & 1.8397 \\
\hline & & $P_{2}$ & 0.8096 & 1.3559 & 1.6136 \\
\hline & & $P_{3}$ & 1.3383 & 2.2415 & 2.6674 \\
\hline \multirow{3}{*}{15} & \multirow{3}{*}{110} & $P_{1}$ & 0.8503 & 1.9872 & 2.2579 \\
\hline & & $P_{2}$ & 0.9933 & 1.6636 & 1.9798 \\
\hline & & $P_{3}$ & 1.6420 & 2.7501 & 3.2728 \\
\hline \multirow{3}{*}{20} & \multirow{3}{*}{95} & $P_{1}$ & 0.9830 & 2.2975 & 2.6104 \\
\hline & & $P_{2}$ & 1.1482 & 1.9231 & 2.2885 \\
\hline & & $P_{3}$ & 1.8980 & 3.1789 & 3.7831 \\
\hline \multirow{3}{*}{25} & \multirow{3}{*}{85} & $P_{1}$ & 1.1000 & 2.5709 & 2.9210 \\
\hline & & $P_{2}$ & 1.2846 & 2.1516 & 2.5605 \\
\hline & & $P_{3}$ & 2.1236 & 3.5567 & 4.2327 \\
\hline
\end{tabular}

\section{Nomenclature}

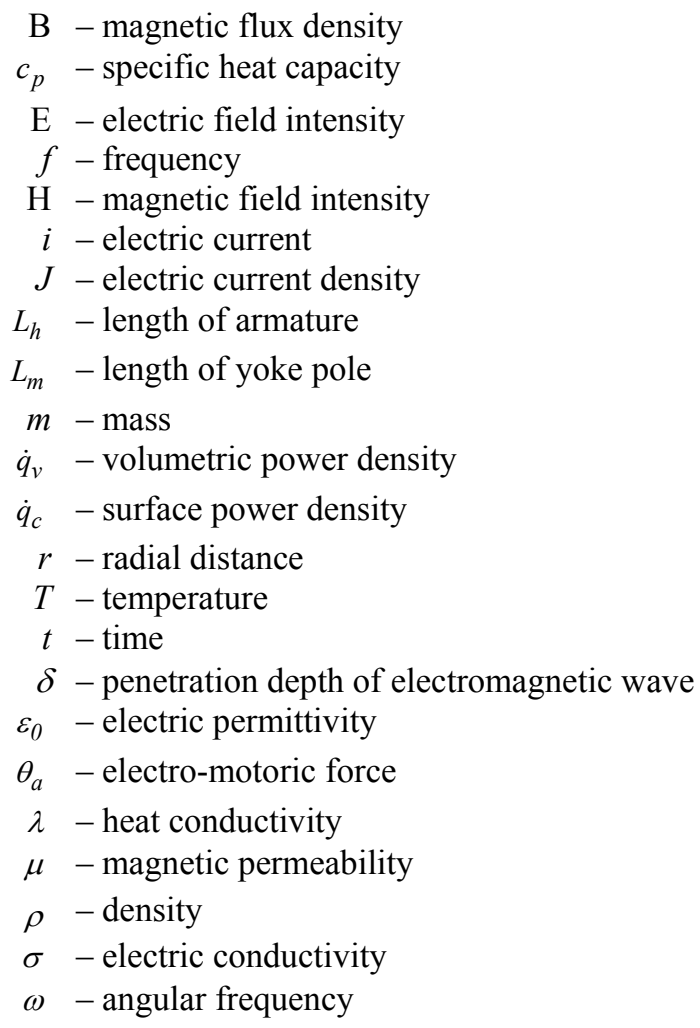




\section{References}

Angadi S., Jackson S. and Choe S. (2009): Reliability and life study of hydraulic solenoid valve. Part 1: a multi-physics finite element model. - Engineering Failure Analysis, S. vol.16, No.3, pp.874-887.

Bottauscio O., Chiampi M. and Manzin A. (2004): Different finite element approaches for electromechanical dynamics. - IEEE Transactions on Magnetics, S. vol.40, No.2, pp.541-544.

Bronstein I.N., Semendjajew K.A., Musiol G. and Mühlig H. (2000): Mathematics pocket-book. - Berlin: Edition Harri Deutsch.

Burg K., Haf H. and Wille F. (1994): High Mathematics for Engineers Bd. 4 Vector Analysis and Complex Analysis. Berlin: Teubner.

Conraths H.J. (1992): Diss. Elektromagnetische Feld-und Temperaturverteilung bei induktiver Banderwärmung. Numerische Berechnung und Messung. RWTH Aachen.

Dlugosz J. (2005): Complex functions. Theory, examples, tasks. - Wroclaw: Oficyna Wydawnicza GiS.

Grigull U. and Sander H. (1990): Wärmeleitung. Berlin: Springer-Verlag.

Huber B. and Ulbrich H. (2014): Modeling and experimental validation of the solenoid valve of a common rail diesel injector. - SAE Technical Paper., S. 2014-01-0195.

Jackson J.D. (2006): Classical Electrodynamics. - New York: de Gruyter.

Krysinski W. and Wlodarski L. (1998): Mathematics Analysis in Tasks. Part 2. - Warsaw: Wydawnictwo Naukowe PWN.

Leitner R. and Zacharski J. (1998): Outline of High Mathematics. - Warsaw: Wydawnictwo Naukowo-Techniczne.

Lu F., Deng J. and Hu Z. (2014): Impact of control methods on dynamic characteristic of high speed solenoid injectors. - SAE Technical Paper, S. 2014-01-1445.

Mrozynski G. (2003): Electromagnetic Field Theory, Collection of Tasks. - Stuttgart, Leipzig, Wiesbaden: B.G. Tuebner.

Nielsen N. (1906): Hand-Book of the Theory of Gamma Function. - Leipzig: Teubner.

Peng L., Liyun F., Qaisar H., De X., Xiuzhen M. and Enzhe S. (2014): Research on Key Factors and Their Interaction Effects of Electromagnetic Force of High-Speed Solenoid Valve. - he Scientific World Journal. Hindawi Publishing Corporation., Article ID 567242.

Rawa H. (2001): Electricity and Magnetism in Technics. - Warsaw: Wydawnictwo Naukowe PWN.

Sean Hodgson, Mahdi Tavakoli, Minh Tu Pham and Arnaud Leleve (2015): Nonlinear Discontinuous Dynamics Averaging and PWM-Based Sliding Control of Solenoid-Valve Pneumatic Actuators. - IEEE/ASME TRANSACTIONS ON MECHATRONICS, S. vol.20, No.2, APRIL 2015.

Shahroudi K., Peterson D. and Belt D. (2006): Indirect adaptive closed loop control of solenoid actuated gas and liquid injection valves. - SAE Technical Paper, S. 2006-01-0007.

Taler J. and Duda P. (2003): Solution of Straight and Reverse Tasks of Heat Transfer. - Warsaw: Wydawnictwo Naukowo Techniczne.

Tautz H. (1971): Heat Transfer and Temperature Compensation. - Weinheim: Verlag Chemie GMBH.

Wei Ying Lai, Nurfarahin Onn, Collin Howe Hing Tang and Mohamed Hussein (2015): Position Control of Hydraulic Actuators Using Fuzzy Pulse Width Modulation (PWM). - Applied Mechanics and Materials, S. vol.735, pp.294298.

Received: July 26, 2015

Revised: August 31, 2015 